\title{
The Effect of Efferentiectomy and Orchidectomy on the Metabolism of the Epididymis of the Mouse
}

\author{
PAUL R. ELLIOTT ${ }^{1}$ \\ Department of Zoology, The University of Michigan, Ann Arbor, Michigan
}

\begin{abstract}
The purpose of the study is a comparison of respiratory metabolic rates and anaerobic glycolytic activity (lactate accumulation) in homogenates of epididymides from normal, orchidectomized and testosterone replaced-orchidectomized mice. Animals subjected to vasa efferentiectomy were used to furnish sperm free homogenates as controls for the homogenates from orchidectomized animals, and to furnish estimates of the contribution of the spermatozoa to these metabolic parameters in homogenates of normal epididymides.

Efferentiectomized mice yield homogenates with a significantly lowered rate of respiratory activity (30\%). Experiments with fractions of these homogenates showed this reduction in activity to be equivalent to the contribution of the spermatozoa in homogenates from normal mice. No significant difference in the rate of respiratory metabolism was observed among homogenates obtained from efferentiectomized, orchidectomized, testosterone replaced-orchidectomized, or testosterone injected-efferentiectomized mice.

Efferentiectomy also resulted in a lowered rate of anaerobic glycolytic activity in vitro. No further reduction or elevation of this activity was observed in homogenates from orchidectomized or testosterone injected animals. Further study indicated this loss following efferentiectomy to be due to a reduced glycolytic activity in the epididymal epithelium rather than to the absence of spermatozoan contribution to the metabolism.

The evidence presented supports the hypothesis that the presence of some component of the spermatozoa or the fluids in which they reside controls the activation or inhibition of a segment of the lactic dehydrogenase activity which is responsible for the secretion of lactic acid into the epididymal canal for spermatozoan utilization.
\end{abstract}

It has been well documented (cf. Mann, '54) that of all the factors which influence reproductive physiology in higher animals, hormones are of principal importance. The androgens in particular are linked intrinsically with the production of seminal plasma, with ejaculation, and with other individual roles of the male accessory organs.

There exist a number of well defined effects of androgen variation on the epididymis and epididymal spermatozoa. Changes in spermatozoan motility were detected by Benoit ('26), and Moore ('27) and changes in the capacity for fertilization by Moore ('28), Young ('29) and Parsons ('50). These androgen effects may or may not be mediated by the epididymis. The influence of androgens on the cytology and physiology of the epididymal epithelium include reports of change in enzyme distribution (Allen and Slater, '57, '58, '59), individual enzyme activities (Allen and Hunter, '60 and Allen and Slater, '61) and secretion by the epididymal epithelium (Dawson and Rowlands, '59).

No explicit realtionship between the epididymis and the maturation of epididymal spermatozoa has been established. In a previous paper (Elliott, '65) it was suggested that one functional role of the epididymal epithelium is the secretion of lactic acid into the epididymal canal for utilization by the spermatozoa. Evidence for this hyothesis includes (1) the presence of lactic acid in the epididymal secretions, (2) the apparent glycolytic character of the metabolism of the epididymal epithelium, (3) the importance of pyruvate in the metabolism of epididymal spermatozoa, and (4) the apical localization of lactic dehydrogenase in the epithelium of the body of the epididymis. In light of the

\footnotetext{
Received Sept. 9, '64. Accepted May 6, '65.

1 N.I.H. predoctoral fellow of the National Cancer Institute (CF-9138). Present address: Biology Department, University of Florida, Gainesville, Florida.
} 
reported effects of androgen variation on specific activities of the epididymal epithelium, support for the hypothesis of lactate secretion might be obtained from the in vivo manipulation of androgen level by orchidectomy and androgen replacement, and subsequent measurement of general metabolic parameters in homogenates of epididymis.

In the previous report (Elliott, '65) no attempt was made to separate the metabolism of the epididymal spermatozoa from that of the epididymal epithelium. For a proper comparison of this tissue under orchidectomized and normal conditions, it was necessary to eliminate any aspects of androgen influence on the metabolism of the spermatozoa. Thus, in this study, the effect of orchidectomy on the rates of aerobic respiration and anaerobic glycolysis in homogenates of epididymis are compared to the same rates in homogenates of epididymides from vasa efferentiectomized animals. The epididymides in the efferentiectomized animals become free of sperm in 40-50 days, but are still under normal androgen influence. In addition, comparison of homogenates of epididymides from efferentiectomized and normal animals would give an indirect estimate of the contribution of the epididymal spermatozoa to the total metabolic activity.

\section{MATERIALS AND METHODS}

All animals used were penbred, male BALB/c jax mice, 150-200 days of age, weighing 20-30 gm. Animals taken for surgical treatment were operated upon with the aid of sodium pentobarbitol ("Sodium Nembutal," Abbott Lab.) anesthesia; $0.7 \mathrm{mgm}$ pentobarbitol in $0.9 \%$ saline per gram mouse body weight. Operations performed were bilateral orchidectomy and bilateral vasa efferentiectomy. Care was taken to protect the vascular supply of the epididymides and testes during the operation. The operated animals were used for study 60-80 days following surgical treatment.

For hormone replacement studies, animals orchidectomized 50-60 days previously were injected subcutaneously with $100 \mathrm{mgm}$ of testosterone proprionate ("Oreton," Schering) daily for 15 days and sacrificed on the sixteenth day. Testosterone injections of normal and efferentiectomized animals were performed in the same manner.

\section{Homogenization and measurement of activity}

The full methods for measurement of optimal respiratory activity (oxygen uptake) and of anaerobic glycolytic activity (lactate accumulation and net phosphate esterification) in $10 \%(\mathrm{w} / \mathrm{v})$ homgenates of epididymis have been presented previously (Elliott, '65). Homogenates to be used for respiratory measurements were prepared in buffered, isotonic sucrose $(0.25 \mathrm{M}$ sucrose in $0.025 \mathrm{M}$ phosphate buffer, $\mathrm{pH}$ 7.4). The optimal medium contained (final concentration): $0.025 \mathrm{M}$ phosphate buffer, $\mathrm{pH} 7.4,0.01 \mathrm{M}$ glucose, $0.01 \mathrm{M}$ pyruvate, $0.01 \mathrm{M}$ fumarate, $0.01 \mathrm{M}$ glutamate, $0.011 \mathrm{M}$ magnesium chloride, $0.02 \mathrm{M}$ nicotinamide, 5.5 $\times 10^{-4} \mathrm{M}$ diphosphopyridine nucleotide, $4.4 \times 10^{-3} \mathrm{M}$ adenosine triphosphate, and $1.0 \times 10^{-5} \mathrm{M}$ cytochrome c. Measurements of anaerobic glycolytic activity (under nitrogen) were carried out on homogenates prepared in buffered, isotonic potassium chloride $(8.0 \mathrm{ml}$ of $0.02 \mathrm{M}$ potassium bicarbonate per liter of $0.154 \mathrm{M}$ potassium chloride). The optimal medium contained (final concentrations): $0.024 \mathrm{M}$ phosphate buffer, pH 7.4, $0.05 \mathrm{M}$ potassium bicarbonate, $0.01 \mathrm{M}$ potassium fluoride, $6.6 \times$ $10^{-3} \mathrm{M}$ magnesium chloride, $0.04 \mathrm{M}$ nicotinamide, $3.3 \times 10^{-3} \mathrm{M}$ fructose-1-6-diphosphate, $3.3 \times 10^{-3} \mathrm{M}$ glucose, and $6.6 \times$ $10^{-3} \mathrm{M}$ pyruvate.

The homogenates were checked routinely for the presence and condition of spermatozoa.

All results were analyzed statistically and are reported as the average of duplicate flasks in $\mathrm{N}$ experiments with the corresponding $95 \%$ confidence limits $\left(t_{n} \times S_{\bar{x}}\right.$ where $S_{\vec{x}}$ is the standard error of the mean and $t_{n}$ is the " $t$ " table value for $n$ degress of freedom). Data are reported as net values (exogenous minus endogenous) using the " $Q$ " notation.

$-\mathrm{QO}_{2}(\mathrm{~N})$... micromoles of oxygen taken up per milligram tissue nitrogen per hour in air. 


\section{$\mathrm{Q}_{\mathrm{L}} \mathrm{N}_{2}(\mathrm{~N})$. . micromoles of lactate pro- duced per milligram tissue nitrogen per hour in nitro- gen. \\ $-\mathrm{QP}_{\mathrm{P}} \mathrm{N}_{2}(\mathrm{~N})$... micromoles of inorganic phosphate esterified per milli- gram tissue nitrogen per hour in nitrogen.}

Because of the significant effect of orchidectomy on the per cent total nitrogen of epididymal tissue, and the absence of information on the nature of the nitrogen loss, the results are also given as units of activity per $30 \mathrm{mgm}$ wet weight of tissue $(0.3$ $\mathrm{ml}$ of $10 \% \mathrm{w} / \mathrm{v}$ homogenate) to allow full interpretion of the data.

\section{EXPERIMENTAL RESULTS}

All measurements were carried out simultaneously on homogenates of kidney from the same animal for the purpose of comparison with results already in the literature. In this regard, many renotropic effects of androgen variation have been reported. The relationship of renal weight and protein content to androgen level is discussed by Dorfman and Shipley ('56). An effect of orchidectomy on phosphatase activity (Kochakian, '47), amino acid oxidase (Clark et al., '43) and arginase activity (Kochakian, '47) in the kidney has been shown.

In the present study, no significant variation in the rate of oxygen uptake or of glycolytic activity was observed in homogenates of kidney from normal, operated or testosterone injected mice.

\section{Androgen effects on oxygen uptake by epididymal homogenates}

The results of measurement of oxygen uptake by homogenates of epididymides from normal, operated, or testosterone injected mice are shown in table 1. All surgically treated animals yielded epididymides with lowered rates of oxygen uptake in vitro on either a mgm tissue or mgm total nitrogen basis. No differences ( $95 \%$ confidence limits) were observed among homogenates of epididymides from orchidectomized, efferentiectomized or testosterone replaced-orchidectomized mice. Similarly, testosterone injection of normal and efferentiectomized mice resulted in no significant change in the oxygen uptake from that observed in the respective untreated animals.

\section{Efferentiectomy and oxygen uptake}

Efferentiectomized mice were originally intended as controls to furnish metabolic data without the interference of concomitant sperm metabolism and for comparison with sperm free epididymides obtained from orchidectomized animals. However, the magnitude of the loss of respiratory activity following efferentiectomy and orchidectomy ( $30 \%$, table 1 ) and the absence of any restoration of activity following testosterone replacement, made imperative the estimation of the contribution of the epididymal spermatozoa to the respiratory activity observed in homogenates of normal epididymides.

TABLE 1

Oxygen uptake by homogenates of epididymis from normal, operated and testosterone injected mice. The medium was optimal for homogenates of normal epididymis

\begin{tabular}{lccrr}
\hline \multicolumn{1}{c}{$\begin{array}{c}\text { Condition } \\
\text { of mouse }\end{array}$} & $\begin{array}{c}\text { mgm Nitrogen } \\
\text { per ml } \\
\text { homogenate }\end{array}$ & $\begin{array}{c}\text { Oxygen } \\
\text { uptake }\end{array}$ & $-\mathrm{QO}_{2}(\mathrm{~N})$ & $\mathrm{N}$ \\
\hline Normal & $1.3 \pm 0.2$ & $46.5 \pm 3.9$ & $5.5 \pm 0.9$ & 8 \\
Efferentiectomized & $1.25 \pm 0.8$ & $30.1 \pm 2.3$ & $3.8 \pm 0.5$ & 11 \\
Orchidectomized & $1.0 \pm 0.6$ & $28.6 \pm 4.1$ & $3.9 \pm 0.6$ & 6 \\
$\begin{array}{l}\text { Testosterone replaced-orchid. } \\
\text { Testosterone injected-normal }\end{array}$ & $1.1 \pm 0.07$ & $25.7 \pm 6.2$ & $3.1 \pm 0.7$ & 5 \\
$\begin{array}{l}\text { Testosterone injected- } \\
\text { efferentiectomized }\end{array}$ & $1.25 \pm 0.1$ & $47.2 \pm 5.1$ & $5.6 \pm 1.0$ & 3 \\
\hline
\end{tabular}

1 Microliters of oxygen taken up per $30 \mathrm{mgm}$ tissue $(0.3 \mathrm{ml} 10 \%$ homogenate) per hour.

Values reported above are averages of duplicate flasks in $\mathrm{N}$ experiments followed by the $95 \%$ confidence limits. Value of $N$ is shown in last column. 
Three milliliters of $10 \%$ homogenates of epididymides from normal and efferentiectomized mice were rough fractionated at $500 \times \mathrm{g}$ for ten minutes in a Misco high speed centrifuge at $0^{\circ} \mathrm{C}$. The supernatant was removed, the pellet resuspended in $3.0 \mathrm{ml}$ of buffered, isotonic sucrose and the centrifugation step repeated. The wash supernatant was removed by capillary pipette and added to the original supernatant. The pellet was suspended in 3.0 $\mathrm{ml}$ of buffered isotonic sucrose. Aliquots of the whole homogenate (" $\mathrm{H}$ "), supernatant ("S") and pellet ("P") fractions were frozen for nitrogen analysis. The supernatant fraction, examined micro- scopically, was found to be nearly devoid of whole cells, nuclei and sperm, but contained intact mitochondria. In homogenates of normal epididymides, pellet fractions contained large numbers of intact sperm, and in both homogenates pellet fractions contained nuclei and cell debris as well as a few whole cells. Oxygen uptake was measured on the optimal medium for epididymal homogenates using $0.3 \mathrm{ml}$ of whole homogenate or pellet fraction, $0.6 \mathrm{ml}$ of the supernatant fraction and 0.9 $\mathrm{ml}$ of the reconstituted supernatant plus pellet system.

The results of measurement of oxygen uptake by the whole and fractionated ho-

TABLE 2

Oxygen uptake by whole homogenates (" $H$ "), supernatant (" $S$ ") and pellet ("P") fractions of epididymides of normal and efferentiectomized mice. All measurements performed in optimal medium for normal epididymal homogenates

\begin{tabular}{|c|c|c|c|c|c|c|c|}
\hline \multirow[b]{2}{*}{$\begin{array}{l}\text { Homogenate } \\
\text { or fraction }\end{array}$} & \multirow[b]{2}{*}{$\underset{\text { used }}{\operatorname{ml}}$} & \multicolumn{3}{|c|}{ Normal epididymis } & \multicolumn{3}{|c|}{ Efferentiectomized epididymis } \\
\hline & & $\begin{array}{l}\underset{\text { Nitrogen }}{\text { per ml }} \\
\text { per }\end{array}$ & $\begin{array}{c}\text { Oxygen } 1 \\
\text { uptake }\end{array}$ & $-\mathrm{QO}_{2}(\mathrm{~N})$ & $\begin{array}{l}\text { mgm } \\
\text { Nitrogen } \\
\text { per ml }\end{array}$ & $\begin{array}{c}\text { Oxygen } 1 \\
\text { uptake }\end{array}$ & $-\mathrm{QO}_{2}(\mathrm{~N})$ \\
\hline "H" & 0.3 & $1.2 \pm 0.03$ & $38.2 \pm 4.2$ & $5.2 \pm 0.9$ & $1.2 \pm 0.01$ & $25.2 \pm 4.7$ & $3.4 \pm 0.6$ \\
\hline "S" & 0.6 & $0.3 \pm 0.01$ & $22.4 \pm 2.8$ & $5.1 \pm 1.3$ & $0.3 \pm 0.01$ & $19.7 \pm 3.0$ & $4.8 \pm 0.2$ \\
\hline "P" & 0.3 & $0.4 \pm 0.01$ & $12.9 \pm 1.2$ & $4.4 \pm 0.7$ & $0.3 \pm 0.02$ & $3.7 \pm 0.8$ & $1.8 \pm 0.06$ \\
\hline "S" $\mathbf{S}$ " "P"” & 0.9 & $0.4 \pm 0.01$ & $35.6 \pm 5.7$ & $4.7 \pm 1.1$ & $0.4 \pm 0.01$ & $26.3 \pm 5.2$ & $3.6 \pm 0.4$ \\
\hline
\end{tabular}

1 Results in these columns are expressed as microliters of oxygen taken up per $30 \mathrm{mgm}$ tissue (0.3 ml

$10 \%$ homogenate) or equivalent amount of fraction of homogenate per 60 minute measurement.
Values reported above are averages of duplicate flasks in $N$ experiments followed by the $95 \%$ confidence limits. $\mathbf{N}=3$ for all data reported in this table.

TABLE 3

Lactate accumulation and phosphate esterification in homogenates of epididymides from normal, operated and testosterone injected mice. The medium was optimal for anaerobic glycolytic activity by homogenates of normal epididymis

\begin{tabular}{|c|c|c|c|c|c|c|}
\hline $\begin{array}{l}\text { Condition } \\
\text { of mouse }\end{array}$ & $\begin{array}{c}\text { Single } \\
\text { epididymis } \\
\text { mgm wet } \\
\text { weight }\end{array}$ & $\begin{array}{c}\text { mgm } \\
\text { Nitrogen } \\
\text { per mi } \\
\text { homogenate }\end{array}$ & $L^{1}$ & $Q_{L}^{N_{2}}(N)$ & $-\mathbf{Q}_{\mathbf{P}}^{\mathbf{N}_{2}}(\mathbf{N})$ & $\mathbf{N}$ \\
\hline Normal & $34.7 \pm 2.4$ & $1.2 \pm 0.11$ & $8.5 \pm 0.3$ & $36.3 \pm 1.4$ & $5.4 \pm 1.3$ & 12 \\
\hline Efferentiectomized & $30.4 \pm 1.2$ & $1.25 \pm 0.23$ & $6.5 \pm 0.5$ & $26.7 \pm 2.1$ & $2.2 \pm 1.2$ & 8 \\
\hline Orchidectomized & $10.5 \pm 0.9$ & $0.98 \pm 0.2$ & $5.1 \pm 1.0$ & $23.6 \pm 3.5$ & $-1.2 \pm 1.1$ & 7 \\
\hline $\begin{array}{l}\text { Testosterone } \\
\text { replaced-orchid }\end{array}$ & $23.0 \pm 3.2$ & $1.07 \pm 0.24$ & $6.8 \pm 1.3$ & $27.4 \pm 5.7$ & $-2.6 \pm 1.4$ & 7 \\
\hline $\begin{array}{l}\text { Testosterone } \\
\text { injected-normal }\end{array}$ & - & $1.21 \pm 0.5$ & $8.3 \pm 1.1$ & $37.6 \pm 3.3$ & $4.0 \pm 1.4$ & 3 \\
\hline $\begin{array}{l}\text { Testosterone } \\
\text { injected- } \\
\text { efferentiectomized }\end{array}$ & - & $1.19 \pm 0.7$ & $5.0 \pm 0.6$ & $21.2 \pm 3.1$ & $2.8 \pm 1.9$ & 3 \\
\hline
\end{tabular}

1 Micromoles of lactate accumulated by $30 \mathrm{mgm}$ of tissue ( $0.3 \mathrm{ml} 10 \%$ homogenate) during a 40 minute incubation.

Values reported above are averages of duplicate flasks in $\mathbf{N}$ experiments followed by the $95 \%$ confidence limits. Values for $\mathrm{N}$ are shown in the last column. 
mogenates (table 2) indicate the loss of respiratory activity resulting from efferentiectomy to be due to the absence of spermatozoa. A significant difference ( $95 \%$ confidence limits) in the rate of oxygen uptake appears between the sperm containing pellet fraction of normal epididymal homogenates and the corresponding sperm free fraction from the efferentiectomized epididymal homogenates. No significant difference is observed between the supernantant fractions (from the epithelial components of the tissue) of these two homogenates. On this basis, under the conditions imposed in this experiment, the contribution of sperm to the respiratory activity in whole homogenates is about $30 \%$, approximating that loss of activity following efferentiectomy.

\section{Relationship of androgen level to glycolysis in epididymal homogenates}

In table 3 are reported the results of experiments on anaerobic lactate accumulation and phosphate esterification by homogenates of epididymides from normal, operated and testosterone injected mice. The reaction medium was optimal for homogenates of normal epididymides.

It is evident that efferentiectomy again results in a significant loss of activity in these homogenates compared to homogenates from nonoperated animals. In addition, although the rate of lactate accumulation in homogenates from orchidectomized animals was consistently lower than in those obtained from efferentiectomized animals, there was no statistically significant difference.

Similarly, the rate of lactate accumulation of homogenates of epididymides from testosterone replaced-orchidectomized mice was consistently, but not statistically higher than in homogenates from orchidectomized animals, and did not exceed that rate in homogenates from efferentiectomized animals.

The change in phosphate esterification to a net negative balance (phosphate release) in homogenates of epididymides from orchidectomized and testosterone replaced-orchidectomized animals (table 3 ) is the most obvious effect of androgen variation in this system. This shift in overall phosphate balance apparently is not due to the absence of sperm since homogenates of efferentiectomized epididymides maintain a net esterification of phosphate. If it be due to orchidectomy, the effect is not reversible under these experimental conditions, since testosterone replacement results in homogenates which also show a net negative balance.

\section{Efferentiectomy and glycolytic activity}

The lowered rate of lactate accumulation in homogenates of epididymides from efferentiectomized animals is similar to that observed in the measurements of respiratory activity. Fractionation experiments identical to those described in that section were carried out to check for the relationship of sperm absence to this loss of activity. Anaerobic lactate accumula-

TABLE 4

Lactate accumulation and phosphate esterification in fractions and whole homogenates of epididymides from normal and efferentiectomized mice. The medium was optimal for homogenates of normal epididymis

\begin{tabular}{|c|c|c|c|c|c|c|c|}
\hline \multirow{2}{*}{$\begin{array}{c}\text { Homogenate } \\
\text { or fraction }\end{array}$} & \multirow{2}{*}{$\underset{\text { used }}{\mathrm{ml}}$} & \multicolumn{3}{|c|}{ Normal epididymis } & \multicolumn{3}{|c|}{ Efferentiectomized epididymis } \\
\hline & & Nitrogen 1 & $\mathrm{~L}^{2}$ & $Q_{L}^{N_{2}}(N)$ & Nitrogen ${ }^{1}$ & $L^{2}$ & $Q_{L}^{N_{2}}(N)$ \\
\hline "H" & 0.3 & $1.2 \pm 0.2$ & $8.2 \pm 0.6$ & $34.5 \pm 3.3$ & $1.3 \pm 0.2$ & $6.2 \pm 0.8$ & $25.9 \pm 2.1$ \\
\hline "S" & 0.6 & $0.4 \pm 0.02$ & $7.0 \pm 0.8$ & $46.1 \pm 2.1$ & $0.4 \pm 0.06$ & $5.6 \pm 0.3$ & $35.5 \pm 2.7$ \\
\hline " $\mathrm{P} "$ & 0.3 & $0.4 \pm 0.1$ & $0.8 \pm 0.9$ & $14.2 \pm 9.6$ & $0.2 \pm 0.07$ & $0.1 \pm 0.02$ & $2.8 \pm 0.6$ \\
\hline "S"+ "P" & 0.9 & $0.3 \pm 0.1$ & $6.3 \pm 0.1$ & $35.2 \pm 4.6$ & $0.4 \pm 0.1$ & $4.4 \pm 1.7$ & $21.2 \pm 3.1$ \\
\hline
\end{tabular}

1 Milligrams of nitrogen per ml whole homogenate or fraction.

2 Micromoles lactate accumulated (net) per $30 \mathrm{mgm}$ tissue ( $0.3 \mathrm{ml} 10 \%$ homogenate or equivalent amount of fraction) per 40 minute incubation.

Values reported above are the averages of duplicate flasks in $N$ experiments followed by the $95 \%$ confidence limits. $\mathrm{N}=3$ for all data above. 
tion was measured in supernatant ("S"), pellet ("P") and reconstituted supernatant plus pellet fractions and in whole homogenates. In the results (table 4 ) note that the activity accountable to spermatozoan glycolysis is negligible ( $10 \%)$, and thus the difference in activity between homogenates from normal and efferentietcomized animals appears to be due to changes in the epididymal epithelium. This is borne out by the significant difference ( $95 \%$ confidence limits) between the respective supernatant fractions which contain no sperm.

\section{Location of the effect of efferentiectomy}

LePage ('50), Chernick et al. ('51) and Colowick et al. ('47) have pointed out the sensitivity of the hexokinase reaction to hormonal interference, both in vivo and in vitro. Since a lowered rate of glucose phosphorylation could properly account for the lowered glycolytic activity in this tissue after efferentiectomy, this rate was estimated in homogenates of epididymides from normal and efferentiectomized animals.

The results (table 5) indicate that glucose phosphorylation is occurring at the same rate in homogenates from efferentiectomized animals as from the unoperated mice. In both homogenates the accumulation of lactate is seen to be glucose sensitive, requires adenosine triphosphate, and under conditions where limiting fructose1-6-diphosphate is supplemented by glu- cose, the lactate produced exceeds that expected from the glycolysis of the hexose diphosphate alone. Three further observations suggest that hexokinase is not affected by efferentiectomy. The per cent stimulation of activity in the presence of glucose (line 2, table 5) is equivalent in both homogenates. The rate of lactate accumulation is significantly lower in homogenates from efferentiectomized animals when fructose-1-6-diphosphate is sole substrate (lines 1, 5; table 5). Third, homogenates from efferentiectomized animals retain a net phosphate esterification (table 3 ). These results argue that the inhibition of glycolysis due to efferentiectomy is beyond the initial phosphorylation reactions.

If this inhibition is at a step in the enzymatic conversion of hexose diphosphate to 3-phosphoglyceric acid, it should result in a lowered generation of reduced diphosphopyridine nucleotide (DPNH). In the fluoride blocked system, the accumulation of lactate is proportional to the DPNH generated in the glycolytic pathway. Thus, supplementing the medium with DPNH should indicate whether such an inhibited step is present.

In homogenates from normal mice, added DPNH resulted in an increased lactate accumulation as expected (table 6). The increase in homogenates from efferentiectomized mice was not significant. Since both pyruvate and DPNH were nonlimiting at the high concentration, the results suggest that the lowered glycolytic

TABLE 5

The effect of glucose and fructose-1-6-diphosphate (HDP) on lactate accumulation and phosphate esterification in homogenates of epididymides from normal and efferentiectomized mice. Data are presented as micromoles of lactate or phosphate produced per $30 \mathrm{mgm}$ tissue homogenate per 60 minute incubation.

\begin{tabular}{|c|c|c|c|c|c|}
\hline \multicolumn{2}{|c|}{$\mu$ Moles added } & \multicolumn{2}{|c|}{ Normal epididymis } & \multicolumn{2}{|c|}{ Efferentiectomized epididymis } \\
\hline GIucose & HDP & $\mu$ Moles I & $\mu$ Moles $\mathbf{P}$ & $\mu$ Moles L & $\mu$ Moles $\mathbf{P}$ \\
\hline 0 & 1 & $1.7 \pm 0.7$ & $0.5 \pm 0.2$ & $1.0 \pm 0.25$ & $0.8 \pm 0.3$ \\
\hline 5 & 1 & $3.5 \pm 0.5$ & $-0.5 \pm 0.2$ & $2.2 \pm 0.6$ & $0.1 \pm 0.15$ \\
\hline 5 & $1^{1}$ & $1.6 \pm 0.2$ & - & $1.0 \pm 0.4$ & - \\
\hline 5 & 0 & $0.4 \pm 0.01$ & $0.9 \pm 0.4$ & 0 & $0.9 \pm 0.15$ \\
\hline 0 & 5 & $7.9 \pm 0.9$ & - & $4.2 \pm 1.0$ & - \\
\hline
\end{tabular}

1 ATP deleted from the otherwise optimal medium for homogenates of normal epididymides.

Values reported above are averages of duplicate flasks in $\mathbf{N}$ experiments followed by the $95 \%$ confidence limits. $\mathbf{N}=\mathbf{3}$ for all data. 
activity in epididymides from efferentiectomized mice is involved in the terminal glycolytic step, the conversion of pyruvate to lactate.

\section{DISCUSSION}

The research which most clearly delineates the complexity of the epididymis and its responses to androgen variation is that of Allen and Slater ('57, '58, '59, '61) and Allen and Hunter ('60). On the basis of cytochemical localization of enzymatic activity these authors established nine distinct regions (lobes) of the mouse epididymis. Abrupt changes in cell type, enzyme localization and enzyme activity occur between the epithelium of one region and adjacent regions. Since the epididymis is comprised of a single tubule, this regional differentiation implies a high degree of functional complexity. Similar morphological and cytochemical differentiation of the epididymal epithelium has been observed in the epididymis of the rat (Reid and Cleland, '57) and in the rabbit (Nicander, '57).

This functional complexity is accentuated by the varied response of individual enzymes to orchidectomy, efferentiectomy and testosterone replacement. Allen and Slater ('61) for example, report that diphosphopyridine nucleotide diaphorase activity is homogeneously distributed in the cytoplasm of the epithelial cells, is not affected by efferentiectomy, is depressed by orchidectomy and restored to normal activity by testosterone replacement. On the other hand, lactic dehydrogenase-diphosphopyridine nucleotide diaphorase activity has an apical localization in the epi- thelial cells of certain regions of the epididymis, and is homogeneous within the cells of other regions. The activity of this enzyme is reduced by efferentiectomy and orchidectomy, but testosterone treatment of orchidectomized animals restores neither the level of activity nor the apical distribution pattern of the normal epididymis. Allen ('61) has shown further that only the fraction of lactic dehydrogenase activity which is apically situated in the cell is reduced by efferentiectomy.

In this study, the response of the epididymis to in vivo androgen variation is obvious only in the data on wet weight and tissue nitrogen content. The absence of an androgen effect on in vitro measurements of general aerobic and anaerobic metabolism is deserving of further comment. The failure to detect such a response in the present studies is complicated by a number of factors. The inhibition of anaerobic glycolysis in homogenates of epididymides from efferentiectomized animals may mask any effects resulting from orchidectomy or testosterone treatment. The low oxidative metabolism of homogenates of epididymis (Elliott, '65) and relatively high contribution of the spermatozoa to this activity $(30 \%$ of the respiration of an homogenate of normal epididymides) make difficult the detection of any variations in respiratory rate due to changes in androgen level. The use of whole homogenates of epididymides, in light of the regional differentiation of this organ and variable response of individual regions to androgen change would further limit the detection of specific androgen effects. Probably most significant

TABLE 6

The effect of added diphosphopyridine nucleotide (DPNH) on lactate accumulation and phosphate esterification in homogenates of epididymides from normal and efferentiectomized mice. The medium was otherwise optimal for homogenates of normal epididymides. Data are presented as micromoles of lactate or phosphate produced by $30 \mathrm{mgm}$ of tissue homogenate during a 40 minute incubation.

\begin{tabular}{|c|c|c|c|c|}
\hline \multirow{2}{*}{$\begin{array}{l}\text { DPNH: final } \\
\text { conc. (molar) }\end{array}$} & \multicolumn{2}{|c|}{ Normal epididymis } & \multicolumn{2}{|c|}{ Efferentiectomized epididymis } \\
\hline & $\mu$ Moles L & $\mu$ Moles $\mathrm{P}$ & $\mu$ Moles L & $\mu$ Moles $\mathbf{P}$ \\
\hline 0.0 & $8.1 \pm 2.1$ & $-1.6 \pm 0.3$ & $5.8 \pm 1.6$ & $1.0 \pm 0.3$ \\
\hline $6.6 \times 10^{-4}$ & $13.6 \pm 2.9$ & $2.9 \pm 1.1$ & $6.2 \pm 2.2$ & $3.1 \pm 0.3$ \\
\hline $1.3 \times 10^{-3}$ & $11.3 \pm 3.1$ & $3.8 \pm 0.8$ & $6.3 \pm 1.0$ & $3.9 \pm 0.4$ \\
\hline
\end{tabular}

Values reported above are averages of duplicate flasks in $\mathrm{N}$ experiments followed by the $95 \%$ confidence limits. $\mathrm{N}=3$ for all data. 
is that in the measurement of overall metabolic rates involving many enzymes in homogenized tissue, the only limiting condition possible is the reduced level or noncompetitive inhibition of a specific enzyme which then becomes rate limiting for the whole system. This precludes the possibility of detection of androgen effects due to compartmentation of substrates, inhibition of substrate transport, enzyme repression or derepression, and localized competitive enzyme inhibition.

Thus in this general metabolic system it is not surprising that an explicit role of androgen is not detected. However, a separate physiological control mechanism is detectable in the response of this tissue to efferentiectomy. The evidence presented in this study suggests that the activity of lactic dehydrogenase in the epididymal epithelium is inhibited or lowered by efferentiectomy, confirming the cytochemical analysis of Allen and Slater ('61) and Allen ('61) on this tissue. No evidence has as yet been presented with regard to the basis or mechanism of this control, but the fact that it is observed following efferentiectomy suggests that it should be related to sperm presence, either as an exocrine secretion of the testes or spermatozoa, or as some physical phenomenon such as turgidity due to the presence of spermatozoa and fluids in the epididymal canal.

There is no apparent relationship between changes in activity resulting from efferentiectomy and those resulting from androgen removal or replacement. White ('33) reported that ligation of the vasa efferentia of the rat failed to inhibit androgen production or secretion by the testes. Dawson and Rowlands ('59) observed no change in the interstitial cells of the testis following occlusion of the vasa efferentia of the rat. In the present study, homogenates of epididymides from testosterone injected-efferentiectomized animals and from noninjected-efferentiectomized animals maintained identical rates of glycolysis. A consistent reduction of glycolytic activity beyond that due to efferentiectomy was observed in homogenates from orchidectomized mice and this slight effect of androgen was relieved by testosterone replacement. However, there were no conditions found under which glycolytic activ- ity could be elevated to normal rates in homogenates from efferentiectomized or orchidectomized animals.

It is entirely possible that the reduction of glycolytic activity of the epididymis following efferentiectomy, and the similar report by Allen ('61) and Allen and Slater ('61) on lactic dehydrogenase activity have no relationship to epididymal control of spermatozoan maturation and development. However, in conjunction with the evidence reviewed in the introduction of this paper which led to the hypothesis of the secretion of lactic acid by the epididymal epithelium for utilization by the spermatozoa, the presence of a control for that secretion should not be surprising. Indeed, in view of the extended duration of the storage of the spermatozoan in the epididymis (probably about 10-15 days in a sexually inactive mouse) a control mechanism independent of cyclical variations in androgen level would be advantageous. If certain portions of the lactic dehydrogenase activity are as important as the evidence suggests, and if these particular lactic dehydrogenases exist in other tissues of the animal, then uniform control of those enzymes by testosterone could be a disadvantage to the animal. The most obvious source of such a control would be through some factor present only when the spermatozoa and their surrounding fluids are present.

Thus it is suggested that the presence of some component of the spermatozoa or the fluids in which they reside controls the activation or inhibition of a certain segment of the lactic dehydrogenases in the epididymal epithelium which in addition to (or a causal factor of) the predominantly glycolytic metabolism of the epididymis, enhances the non-oxidative removal of DPNH and pyruvate generated in glycolysis, resulting in the secretion of lactic acid for spermatozoan utilization.

\section{LITERATURE CITED}

Allen, J. M. 1961 Multiple forms of lactic dehydrogenase in tissues of the mouse: their specificity, cellular localization, and response to altered physiological conditions, pp. 937-951. In: Wroblewski, F. (Ed.) Multiple molecular forms of enzymes. Annals N. Y. Acad. Sci., 94: 655-1030.

Allen, J. M., and R. L. Hunter 1960 A histochemical study of the enzymes in the epididy- 
mis of normal, castrated and hormone replaced castrated mice separated by zone electrophoresis in starch gels. J. Histochem. CytoChem., 8: 50-57.

Allen, J. M., and J. J. SIater 1957 A chemical and histochemical study of alkaline phosphatase and aliesterase in the epididymis of normal and castrate mice. Anat. Rec., 129; 255273.

1958 A chemical and histochemical study of acid phosphatase in the epididymis of normal, castrate and hormone replaced castrate mice. Anat. Rec., 130: 731-746.

1959 A chemical and histochemical study of enzymes dephosphorylating adenosine phosphate esters in the epididymis of normal, castrated and testosterone proprionate treated castrated mice. Am. J. Anat., 105: 117-139.

- 1961 A cytochemical analysis of the lactic dehydrogenase and diphosphopyridine nucleotide-diaphorase system in the epididymis of the mouse. J. Histochem. Cytochem., 9: $221-233$.

Benoit, J. 1926 Recherches anatomiques, cytologiques et histophysiologiques sur les voies excrétrices du testicules chez les mammiféres. Arch Anat, Strasbourg, 5: 174-412.

Chernick, S. S., I. L. Chaikoff and S. Abraham 1951 Localization of initial block in glucose metabolism in diabetic lever slices. J. Biol. Chem., 193: 793-802.

Clark, L. C. Jr., C. D. Kochakian and R. P. Fox 1943 The effect of castration and testosterone proprionate on d-amino acid oxidase activity in the mouse. Science, 98: 89.

Colowick, S. P., G. T. Cori and M. W. Slein 1947 The effect of adrenal cortex and anterior pituitary extracts and insulin on the hexokinase reaction. J. Biol. Chem., 168; 583-596.

Dawson, R. M. C., and I. W. Rowlands 1959 Glycerylphosphorylcholine in the male reproductive organs of rats and guinea pigs. Quarterly J. Exp. Physiol., 44: 26-34.

Dorfman, R. I., and R. A. Shipley 1956 Androgens. Biochemistry, Physiology and Clinical
Significance, Ch. 13, p. 206. John Wiley and Sons, New York.

Elliott, P. R. 1965 The metabolism of homogenates of the mouse epididymis. J. Cell. and Comp. Physiol., 66: 281-292.

Kochakian, C. D. 1947 The role of hydrolytic enzymes in some of the metabolic activities of steroid hormones. Recent Progress in Hormone Res., 1: 177-216.

LePage, G. A. 1950 A comparison of tumor and normal tissues with respect to factors effecting the rate of anaerobic glycolysis. Cancer Res., 10: 77-88.

Mann, T. 1954 The Biochemistry of Semen. John Wiley and Sons, Inc., New York, New York, $240 \mathrm{pp}$.

Moore, C. R. 1927 A qualitative test for the testis hormone. Proc. Soc. Exp. Biol. and Med., 24: $847-848$.

—_ 1928 On the properties of the gonads as controllers of somatic and psychical characteristics. X. Spermatozoan activity and the testis hormone. J. Exp. Zool., 50: 455-494.

Nicander, L. 1957 On the regional histology and cytochemistry of the ductus epididymis in rabbits. Acta Morph. Neerlando-Scandinavica, 1: $99-118$.

Parsons, U. 1950 Fructose in rabbit semen; a study of normal fluctuations and changes evoked by testosterone and stilboestrol. J. Endocr., 6: 412-422.

Reid, B. L., and K. W. Cleland 1957 The structure and function of the epididymis. I. The histology of the rat epididymis. Australian J. Zool., 5: 223-246.

White, W. E. 1933 The duration of fertility and the histological changes in the reproductive organs after ligation of the vasa efferentia in the rat. Proc. Royal Soc. (London), s.B., 113: 544-550.

Young, W. C. 1929 A study of the function of the epididymis. II. The importance of the aging process in spermatozia. J. Morph., 48: 475-491. 